\title{
Estimating the Catenary Parameter for Catenary Shape Using the Newton Raphson Iterative Method as a Tool for Extended Reach Well Buildup Section Design
}

\author{
Ohenhen Ikponmwosa* Igbinere Sunday Agbons \\ Department of Petroleum Engineering, University of Benin, PMB1154, Benin City, Nigeria
}

\begin{abstract}
The catenary well profile was first used to design extended reach well buildup section in 1985, ever since then a number of wells have been constructed using this profile. It towers over the constant build (circular arc) profile in terms of advantages. Prominent of which is the reduction of torque and drag. This advantage was restrained by the catenary parameter "a", as "a" determines the shape or trajectory of a catenary shape in any given circumstance. We proffered a solution to estimating the catenary parameter "a" using the Newton-Raphson iteration method for linear equations. This method makes it easy to calculate "a" for almost every desired catenary shape. Also after estimating the values for "a" we went ahead to calculate tensions that will produce that calculated catenary parameter "a" as the parameter is the product of tension at the end of the string and inverse of unit weight. This method of catenary parameter prediction has been used to design overhead electrical cables and predict the extent of sagging of this cables. We used it here to design the path or trajectory of an extended reach well with satisfactory success. Results from the study shows that the use of the Newton-Raphson iterative method for the estimation of catenary parameter "a" for buildup section design of extended reach wells makes it easy for engineers to plan catenary trajectories with available materials and also removes the uncertainties that are inherent in predicting the shape of the trajectory.
\end{abstract}

Keywords: Caternary, String, well, Newton-Raphson, Extended Reach well

DOI: $10.7176 / \mathrm{JETP} / 11-5-04$

Publication date:October $31^{\text {st }} 2021$

\section{Introduction}

Hydrocarbon exploration and sales has been the main stay of Nigeria's economy since it was discovered in 1956. Since its discovery in commercial quantity and a rise in oil prices in the 1970's, oil became a major foreign exchange earner and contributor to GDP, relegating other sectors of the Nigerian economy (Weian, 1988). Globally, the invention of new technologies such as the internal combustion engine and the use if hydrocarbon gasses for electricity generation during the second industrial revolution gave tremendous opportunity towards the utilization of hydrocarbon. Today the world depends heavily on hydrocarbon as one of the major sources of energy. It is estimated that 100.87 bbls of oil equivalent was consumed on a daily basis globally in 2019. Finding crude oil deposits was easy, as wells were dug at sites close to obvious sips, this didn't need expert petro physical surveys to find them and this crude deposits were mostly found close to the surface as seen in the drake well of 1857 (Dune, 2004). As the demand for hydrocarbon and its products began to rise, finding its deposits became increasingly difficult this led to the more sophisticated technologies being developed. With the continuous improvements of science and technology, many advanced scientific and technological improvements have been applied to the petroleum exploration industry and the degree of intelligence in petroleum exploration is constantly improving (Zhang et al., 2020). One of such innovations is the development of directional wells, directionally drilled wells represent an efficient way to reach special targets that are difficult to reach using vertically drilled wells, it has the advantage of reaching many intended targets while minimizing surface construction (Xiaohua et al., 2017) . Also the extended reach well, a type of directional drilling that pushes the frontier technology in drilling limitations (Deli et al., 2009).

When the horizontal displacement of a directional or horizontal well is more than $3000 \mathrm{~m}$ and the horizontal displacement to true vertical depth ratio is equal to or above 2 or the measured depth to true vertical depth ratio is above 2, this directional well is called an extended reach well (Deli et al., 2009). The extended reach well has many advantages in fact, the application of extended reach technology has resulted in increased drainage radii, increased production rate, improved reservoir management reduction in required platforms and well counts and improved field economics (Bhalla, 1996).

So many successful wells have been drilled using the extended reach technology. Well reach has increased significantly in the past decades, in the 80's $3 \mathrm{~km}$ step out was common, this increased in the 1990's to $10 \mathrm{~km}$ and more (Aadnoy et al., 2006). Extended reach wells provide solutions for restricted reservoirs and also help to eliminate additional platforms. In designing ERDs just like every other well, we aim to overcome challenges that construction of this wells might bring.

Usually the build section of an extended reach well is designed with a curve of a constant curvature (circular 
arc) but with the development of the rotary steering drilling technology experts have presented some new types of profiles for designing the build section. These available profiles are; Inverse proportional curve, Catenary profile, Sideway catenary, parabola, sideway parabola (Sun et al. 2013). The design of the well-profile is one of the critical technologies for success in ERD (Payne et al., 1994). In recent years, with extensive application of extended reach wells drilling technology in drilling engineering the problem of shear failure of the drill pipe tool joints caused by large down hole drag and torque has become increasingly prominent. Statistics show that at least 500 drill pipe failure accidents occur each year in oil and gas fields and has become one of the main factors that limit drilling engineering benefits (Deli et al., 2009; Fomin, 2019; Kamenskikh, 2015). An optimum well profile will enable the reach of the well to a greater displacement, by reducing the drag, the torque, the dog leg severity etc. (Mason and Judzis, 1998; Rodman and Swietlik, 1997). Well profile design is one of the critical technologies for success in ERD (Liu and Samuel, 2009), the beneficial reductions in torque and drag achievable with different well shapes such as catenary, parabola and circular arc are enormous. In this paper we chose the catenary well profile and used it to design the buildup section of extended reach well.

The word catenary was first used in the 1600's, it is coined from the Latin word "catena" which is loosely translated to mean chain (Chatterjee and Nita, 2010). The catenary is the natural shape a chain, rope, cables or even drillstring with uniform density will take due to its own weight. The idea behind using the catenary profile for the design of the buildup section has its roots on the assumption that the string being very long and slender, behaves like a tread, hanging under its own weight and if the well or conduit is designed to take that trajectory, the string will naturally hang inside the well without touching the walls of the well, thereby reducing friction completely (Aadnoy et al., 2006).

The catenary profile was first used to in the petroleum industry McClendon in 1985, and the tension in the string is critical to getting the correct shape, if a force used is too high the string will contact the top of the well, if it is too low it will contact the lower side of the well automatically leading to increase in friction (Aadnoy et al., 2006).. The shape of the catenary profile is dependent on the catenary parameter

$y=\operatorname{acosh}\left(\frac{x}{a}\right)$

Where "a" is the catenary parameter and $\mathrm{x}$ is the horizontal displacement in the $\mathrm{x}$ direction. The catenary parameter "a" is the product of the tension at the lowest point of the catenary (or in this case the end of buildup section) and the inverse of unit weight of the string. Most times the unit weight of the string is known but determining the tension at the lowest point is where the problem lies. This research paper suggest a way to easily predict the catenary parameter for a preferred shape with specific vertical and horizontal displacements known and then design the string with materials that will impose the tension at the end of the build.

\section{Theory/Calculation}

The catenary is the natural shape that a uniform density chain or in this case a drilling string takes when it hangs from two points under its own weight, the equation of the catenary is an equation that is used to describe the catenary shape. Deriving the equations used for this paper. Starting with the catenary equation and the equation for estimating the distance along the catenary. The steps taken to achieve the objective of this paper is shown in figure 1. The equation used for this research was derived to fit the shape needed in this design, a method for predicting the catenary parameter was proposed, apply this method to designing the build section of the well with the estimated parameter and calculate the torque and drag that will be contributed by this build section using known models. The newton-Raphson iterative method is one of many ways to finding the root of equations, it is particularly useful for transcendental equations it is a way to quickly find a good approximation for the root of a real valued function $\mathrm{F}(\mathrm{x})=0$. It uses the idea that a continuous and differentiable function can be approximated by a straight line tangent to, it is used to find solutions to transcendental equations where the solutions cannot be obtained using just algebraic methods.

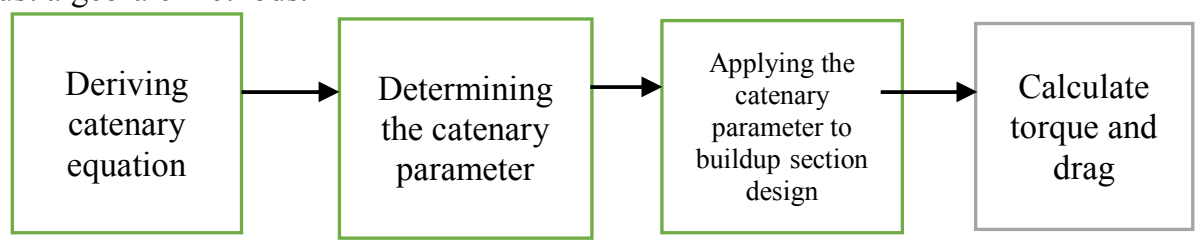

Figure 1. Research methodology

\subsection{Deriving the catenary equation}

To derive the catenary equation, we assume a string of uniform density hanging from 2 points on a wall as seen in figure 2 . 


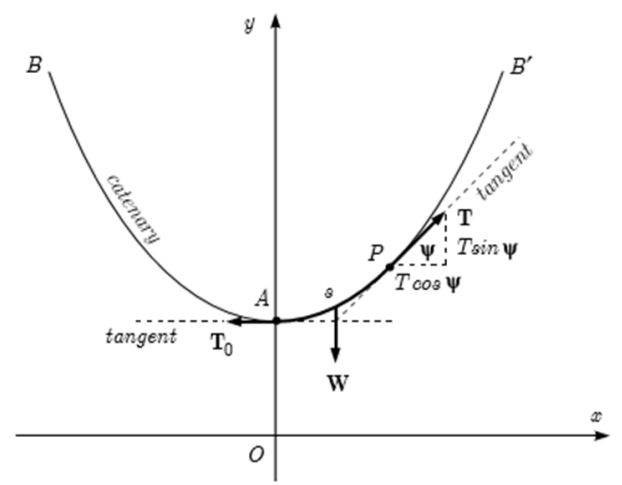

Figure 2. Catenary diagram

But our string will not hang from two points so we use half of the shape with the forces shown acting at both ends resolved.

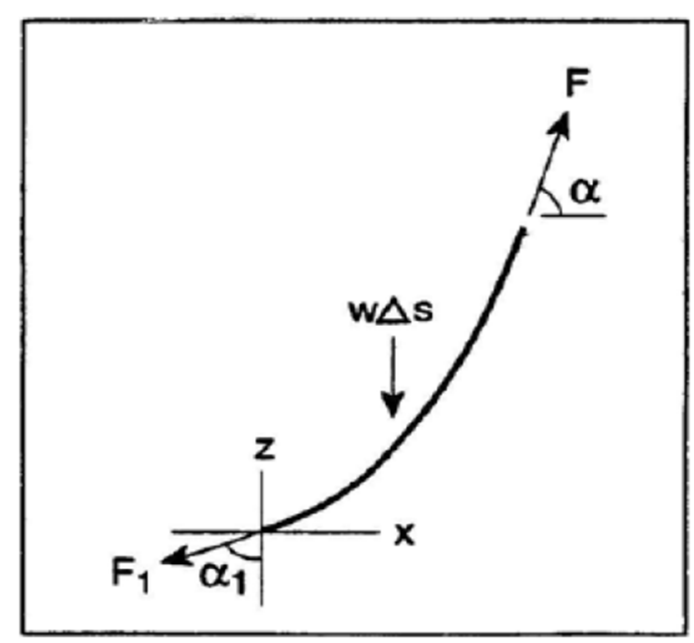

Figure 2: Tangent angle at top of catenary

Figure 3 shows that from the tangent of the angle at the top of the catenary, the forces can be resolved into their different components.

$$
\begin{aligned}
& T \sin \alpha=\gamma s g \\
& T \cos \alpha=T_{o}
\end{aligned}
$$

Also squaring equations 3.3 and 3.2 , and adding the answers gives us

$$
T^{2}\left(\sin ^{2} \propto+\cos ^{2} \propto\right)=T_{o}^{2}+(\gamma s g)^{2}
$$

Dividing 3.3 by 3.2 we have

$$
\frac{T \cos \propto}{T \sin \alpha}=\frac{T_{o}}{\gamma s g}=\tan \propto
$$

From trigonometric identities

$$
\left(\sin ^{2} \propto+\cos ^{2} \propto\right)=1
$$

Therefore,

$$
T^{2}=T_{o}^{2}+(\gamma s g)^{2}
$$

Now introducing the catenary parameter a, which is the ratio of the tension at the lowest point of the catenary to the product of the unit weight and acceleration due to gravity.

$a=\frac{T_{o}}{\gamma g}$

So that equation 4 becomes

and equation 5 , after rearranging becomes

$$
\frac{d y}{d x}=\tan \propto=\frac{s}{a}
$$

$$
T=\gamma g \sqrt{a^{2}+s^{2}}
$$

The differential of the length of a small section of the hanging string is represented as follows:

Therefore rearranging we have that 


$$
\frac{d s}{d x}=\sqrt{1+\left(\frac{d y}{d x}\right)^{2}}
$$

Differentiating equation 6 with respect to $\mathrm{x}$, i.e.

That simplifies to

$$
\frac{d}{d x}\left(\frac{d y}{d x}\right)=\frac{d y}{d x}\left(\frac{s}{a}\right) \frac{d s}{d x}
$$

$$
\frac{d^{2} y}{d x^{2}}=\frac{1}{a} \sqrt{1+\frac{d y^{2}}{d x^{2}}}
$$

Solving the differential equation a variable $\mathrm{P}$ is introduced as

So that equation 12 becomes

$$
P=\frac{d y}{d x} \text { And so } \frac{d p}{d x}=\frac{d^{2} y}{d x^{2}}
$$

$$
\frac{d p}{d x}=\frac{1}{a} \sqrt{1+p^{2}} \text { Or } \mathrm{dx}=\frac{a d p}{\sqrt{1+P^{2}}}
$$

Which can now be easily integrated from a of standard integrals

$$
x=a \int \frac{d p}{\sqrt{1+P^{2}}}=\mathrm{a} \ln \left(p+\sqrt{1+P^{2}}\right)+C_{1}
$$

Therefore

$$
x=\mathrm{a} \sinh P+C_{1}
$$

Where $\ln$ denotes the natural logarithm and $\ln x=\log _{e}^{x}$ and $\sinh ^{-1}$ is the inverse hyperbolic sine function, $C_{1}$ is a constant of integration that can be evaluated by considering figure 1 and noting that at $\mathrm{x}=0, \mathrm{P}=\frac{d y}{d x}=$ $\tan \propto=0$ and $\ln$ "Eq.(1)" $=0$ then $C_{1}=0$

Note also that $\sinh \mathrm{x}$ is the hyperbolic sine of $\mathrm{x}$ and $\sinh \left(\sinh ^{-1} x\right)=x$

$$
P=\sinh \left(\frac{x}{a}\right)=\frac{d y}{d x}
$$

y can now be obtained by a second integration and results can be used to give

$$
y=\int \sinh \left(\frac{x}{a}\right) d x=\operatorname{acosh}\left(\frac{x}{a}\right)+C_{2}
$$

$C_{2}$ Is another constant of integration and can be obtained by a second integration and standard integral results can be made to equal zero if $y=0$ and $x=0$. This means that the low point of the catenary is at $(0, a)$ then the catenary equation $\mathrm{y}=\mathrm{y}(\mathrm{x})$ is

$$
y=a \cosh \left(\frac{x}{a}\right)
$$

The equation for arc length $\mathrm{s}=\mathrm{s}(\mathrm{x})$, equations $\mathrm{y}=\mathrm{y}(\mathrm{x})$, and $\mathrm{x}=\mathrm{x}(\alpha)$, the inclination of the tangent $\alpha=\alpha(\mathrm{x})$

$$
s=\operatorname{asinh}\left(\frac{x}{a}\right)
$$

\section{a. The Newton-Raphson equation "a"}

Consider the Taylor series expansion.

$f(x)=f(a)+\frac{(x-a) f^{i}(a)}{1 !}+\frac{(x-a)^{2} f^{i i}(a)}{2 !}+\cdots+\frac{(x-a)^{n} f^{n}(a)}{n !}$

Considering a simplified Taylor series

$f(x)=f(a)+\frac{(x-a) f^{i}(a)}{1 !}$

Rearranging

$\frac{f(x)-f(a)}{f^{i}(a)}=(x-a)$

Recall that the roots are the value of $\mathrm{x}$ for which $\mathrm{f}(\mathrm{x})=0$, thus

$x=a-\frac{f(a)}{f^{i}(a)}$

In terms of drillstring, we assume lowest point of the catenary is where the build section ends, the tension at this point is as a result of the movement of the string and its interaction with the walls of the well and drilling fluid property. The tension will be highest just before the entire sail section moves when it's being pulled out of the hole. This scenario is what we will be relying on to design the sail section.

But tension in the string cannot be easily determined, for calculating the catenary parameter, so an alternative method for determining the catenary parameter was developed. Considering the equation of the catenary.

$$
\text { At } X=0
$$


$\propto=\tan ^{-1}\left[\sinh \left(\frac{x}{a}\right)\right]$

If the horizontal distance " $\mathrm{h}$ " is known vertical distance " $\mathrm{v}$ " between the catenary supports $\mathrm{P}_{1}, \mathrm{P}_{2}$ are known and the length $\mathrm{L}$ of the string is known, the catenary parameter can be determined.

Given that the coordinates of $\mathrm{P}_{1}, \mathrm{P} 2$ are $(\mathrm{x}, \mathrm{y})$ and $(\mathrm{x}, \mathrm{y})$ respectively and that $\mathrm{P}_{1}$ is at the left of $\mathrm{P}_{2}$ and the $\mathrm{y}$ axis passes through $\mathrm{A}$ (the low point of the catenary) and intersects the $\mathrm{x}$ at 0 , the distance $\mathrm{a}=\mathrm{OA}$, is the unknown parameter. Distance $\mathrm{s}$ along the catenary to the left of the $\mathrm{y}$ axis will be negative and those to the right will be positive. Also assume $\mathrm{y}_{2}>\mathrm{y}_{1}\left(\mathrm{P}_{2}\right.$ is higher than $\left.\mathrm{P}_{1}\right)$.

$h=x_{2}-x_{1}, v=y_{2}-y_{1}, L=s_{2}-s_{1}$

\section{Catenary geometry}

Rearranging catenary equation to predict "a"

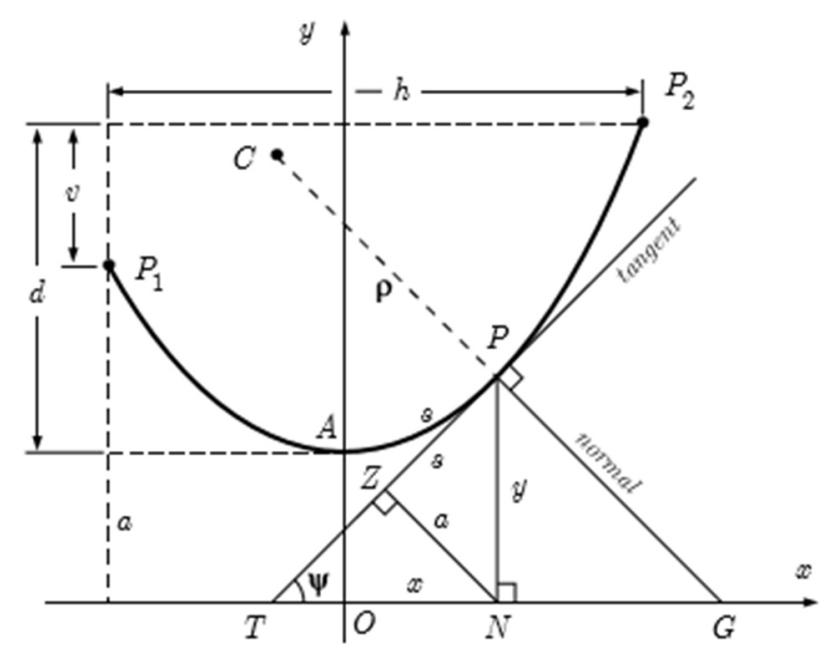

Figure 4. Catenary geometry.

In figure $4 \mathrm{P}_{1}$ and $\mathrm{P}_{2}$ are supports of a hanging chain or catenary of length $\mathrm{L}$. The low point of the catenary is at $\mathrm{A}$, and $\mathrm{p}$ is a point on the catenary at a distance "S" from " $\mathrm{A}$ ". The tangent of the catenary at $\mathrm{P}(\mathrm{x}, \mathrm{y})$ intersects the $\mathrm{x}$ axis at $\mathrm{T}$ at an angle $\alpha$, and the normal to the catenary of $\mathrm{p}$ intersects the $\mathrm{x}$ axis at $\mathrm{G}$ the center of curvature $\mathrm{C}$ lies on the normal and $\rho=C P$ is the radius of curvature by definition the curvature $k$ of a curve $y=F(X)$ at any point $P$ on the curve is the rate of change of direction of the tangent to the curve with respect to arc length and $\mathrm{k}=\frac{d \alpha}{d s}$.

$$
\rho=\operatorname{asec}^{2}, \propto=y \sec , \propto=\frac{y^{2}}{a}=a \cosh ^{2}\left(\frac{x}{a}\right)
$$

From fig. 4, point $\mathrm{p}$ is $\mathrm{x}=\mathrm{ON}$ and $\mathrm{y}=\mathrm{NP}$

$y^{2}=a^{2}+s^{2}$

$$
N Z=y \cos \propto=a, P Z=\text { atan } \propto=s, P G=y \sec \propto=\rho
$$

$\mathrm{S}_{1}$ and $\mathrm{S}_{2}$ are distances $\mathrm{A}$ to $\mathrm{P}_{1}, \mathrm{P}_{2}$ respectively, now using equations $\mathrm{Y}=\mathrm{y}(\mathrm{x})$ and $\mathrm{s}=\mathrm{s}(\mathrm{x})$

$$
\begin{gathered}
v=a\left[\cosh \left(\frac{x_{2}}{a}\right)-\cosh \left(\frac{x_{1}}{a}\right)\right] \\
L=\left[\sinh \left(\frac{x_{2}}{a}\right)-\sinh \left(\frac{x_{1}}{a}\right)\right]
\end{gathered}
$$

Squaring both sides and subtracting one from the other with gives us

$$
\begin{aligned}
& v^{2}=a^{2}\left[\cosh \left(\frac{x_{2}}{a}\right)-\cosh \left(\frac{x_{1}}{a}\right)-2 \cosh \left(\frac{x_{1}}{a}\right) \cosh \left(\frac{x_{2}}{a}\right)\right] \\
& L^{2}=a^{2}\left[\sinh \left(\frac{x_{2}}{a}\right)-\sinh \left(\frac{x_{1}}{a}\right)-2 \sinh \left(\frac{x_{1}}{a}\right) \sinh \left(\frac{x_{2}}{a}\right)\right]
\end{aligned}
$$

And subtracting one from the other with the identity

$$
\cosh ^{2}-\sinh ^{2}=1
$$

$$
L^{2}-v^{2}=a^{2}\left[2 \cosh \left(\frac{x_{1}}{a}\right) \cosh \left(\frac{x_{2}}{a}\right)-2 \sinh \left(\frac{x_{1}}{a}\right) \sinh \left(\frac{x_{2}}{a}\right)\right]
$$

Now using the hyperbolic trigonometric identity

$$
L^{2}-V^{2}=2 a^{2}\left[\cosh \left(\frac{x_{1}-x_{2}}{a}\right)+1\right]
$$


But $\mathrm{x}_{1}-\mathrm{x}_{2}=-\mathrm{h}$, and $\cosh (-\mathrm{h})=\cosh (\mathrm{h})$, and $\cosh \mathrm{A}-1=2 \sinh ^{2}\left(\frac{A}{2}\right)$.

Therefore Eq. 35 becomes

$$
L^{2}-V^{2}=4 a^{2} \sinh ^{2}\left(\frac{h}{2 a}\right) \text { or } \sqrt{L^{2}-V^{2}}=2 \operatorname{asinh}\left(\frac{h}{2 a}\right)
$$

Eq. 36 is transcendental and cannot be solved algebraically, instead it must be solved using numerical methods. One of such methods is the Newton-Raphson iteration.

$$
\begin{aligned}
& a_{n+1}=a_{n}-\frac{f\left(a_{n}\right)}{f^{i}\left(a_{n}\right)} \\
& \mathrm{F}(\mathrm{a})=2 \operatorname{asinh}\left(\frac{h}{2 a}\right)-\sqrt{L^{2}-V^{2}}
\end{aligned}
$$

And its first derivative $\mathrm{f}^{\mathrm{i}}(\mathrm{a})=\frac{d}{d a}(\mathrm{f}(\mathrm{a}))$ is given by

$$
f^{i}(a)=2\left[\sinh \left(\frac{h}{2 a}\right)-\frac{h}{2 a} \cosh \left(\frac{h}{2 a}\right)\right]
$$

\section{3, Results and calculation}

Design and calculations and buildup section trajectory design (well 1)

Well 1 design and calculations

True vertical depth $=3500 \mathrm{~m}$

Coefficient of friction $\mu=0.17$

Density of drilling fluid $\rho=15.065$

Horizontal departure of target $=10000 \mathrm{~m}$

Horizontal departure of end of build $=826 \mathrm{~m}$

Target angle that will allow downward movement of string under its own weight should be less than critical angle of 80.35 degrees

Proposed vertical depth of build section $=1000 \mathrm{~m}$

\subsection{Calculating "catenary parameter a" for field 1}

Note.

- Horizontal distances of point 1 and point 2 respectively $=826 \mathrm{~m}$ and $600 \mathrm{~m}$

Horizontal distance of point 2 is assumed to begin from where that of horizontal departure of point 1 ends, since a catenary cannot be formed without the flexible uniform density string hanging from both sides.

- Proposed depth of catenary section $=1000 \mathrm{~m}$

- Using Pythagoras theory we calculate the hypotenuse of the right angle triangle formed by the horizontal departure and the depth is 1297.02 and adding $0.0119 \mathrm{~m}$ for every 1 meter of string in the hypotenuse to compensate for slagging $=(1297.02+1297.02 * 0.0119) \mathrm{m}$ for point 1 to 0 on the $\mathrm{x}$ axis and $(921.95+921.95 * 0.0119)$ from 0 on the $\mathrm{x}$ axis to point 2 .

- Proposed length of string to use $=(1312+933) \mathrm{m}$ rounded upwards to nearest 10 to account for slagging in pipes. $=2245 \mathrm{~m}$

- Distance from point 1 to point 2 . $\mathrm{H}=1426 \mathrm{~m}$

- Height difference between point 1 and $2 \mathrm{~V}=(1000-700) \mathrm{m}=300 \mathrm{~m}$

- Assuming azimuth difference of (2) for all sections in the calculation of torque and drag for both the catenary and quadratic parabola trajectory or profiles designed.

Table 4.1 iterated values of "a"

\begin{tabular}{|l|l|l|l|l|l|}
\hline $\mathrm{S} / \mathrm{N}$ & \multicolumn{1}{|c}{$\mathrm{a}_{\mathrm{n}}$} & $\mathrm{f}\left(\mathrm{a}_{\mathrm{n}}\right)$ & \multicolumn{1}{c|}{$\mathrm{f}^{\prime}\left(\mathrm{a}_{\mathrm{n}}\right)$} & $\mathrm{C}=\mathrm{f}\left(\mathrm{a}_{\mathrm{n}}\right) / \mathrm{f}^{\prime}\left(\mathrm{a}_{\mathrm{n}}\right)$ & \multicolumn{1}{c|}{$\mathrm{a}_{\mathrm{n}+1}=\mathrm{a}_{\mathrm{n}}$} \\
\hline 1 & 388.8042839 & & & & \\
\hline 2 & 414.4922739 & 15.69001166 & -4.509564586 & -3.479274188 & 417.9715481 \\
\hline 3 & 417.9715481 & 0.230490539 & -4.377956367 & -0.052647975 & 418.024196 \\
\hline 4 & 418.024196 & $5.13644 \mathrm{E}-05$ & -4.376005324 & $-1.17377 \mathrm{E}-05$ & 418.0242078 \\
\hline 5 & 418.0242078 & $2.72848 \mathrm{E}-12$ & -4.376 & $-6.2351 \mathrm{E}-13$ & 418.0242078 \\
\hline
\end{tabular}

After five iterations the value 418.0242078 kept repeating and so that is the value for "a" for those sets of parameters. Using calculated "a" of 418.0242078 to design a catenary path for horizontal distance $826 \mathrm{~m}$ to end of build, we have. 


\subsection{Case 2 calculations and build up section trajectory design (well 2)}

Well Name: well 2

Water Depth: $18 \mathrm{ft}$ (Offshore)

Surface Location: N 169,099.00 m, E 396,123.00 m

Horizontal departure to target from drilling platform: $8096 \mathrm{~m}$

Hole Deviation: Horizontal, Max Angle $90^{\circ}$, TD Azimuth 241.2

Target: sand stone Reservoir about $28 \mathrm{ft}$ thick

True vertical depth $=1805.44 \mathrm{~m}$

Drilling fluid density $=15.5$

Coefficient of friction $\mu=0.17$

Horizontal departure of end of build $=2000 \mathrm{~m}$

Critical angle $=$ not applicable as well is a horizontal extended reach well degrees

Target angle to allow downward movement of string under its own weight should be less than critical angle $=90$ degrees

Assuming average azimuth difference of 2 in all sections for torque and drag calculations

\subsection{Calculations and buildup section design}

Calculating "catenary parameter "a" for well 2

- Horizontal distances of point 1 and point 2 respectively $=2000 \mathrm{~m}$ and $700 \mathrm{~m}$

Note.

Horizontal distance of point 2 is assumed to begin from where that of horizontal departure of point 1 ends, since a catenary cannot be formed without the flexible uniform density string hanging from both sides.

- Proposed depth of build section or depth interval $=1000 \mathrm{~m}$

- Using Pythagoras theory we calculate the hypotenuse of the right angle triangle formed by the horizontal departure and the depth. $=2236.06 \mathrm{~m}$ for point 1 to 0 on the $\mathrm{x}$ axis and 807.11 from 0 on the $\mathrm{x}$ axis to point 2.

- $\quad$ Proposed length of string to use $=(2236.06+707.11+100) \mathrm{m}$ rounded upwards to 2 significant figures to account for slagging in pipes. $=3043.17 \mathrm{~m}$

- Height difference between point 1 and $2=(1005.3-100$.) $\mathrm{m}=905 \mathrm{~m}$

- Assuming azimuth difference of 1 for all sections in the calculation of torque and drag for both the catenary and quadratic parabola trajectory or profiles designed.

- $\quad$ True vertical depth of target from top of well 1805.45

Table 4.2. Iterated values for " $a$ " for well 2

\begin{tabular}{|l|l|l|l|l|l|}
\hline $\mathrm{S} / \mathrm{N}$ & $\mathrm{a}_{\mathrm{n}}$ & $\mathrm{f}\left(\mathrm{a}_{\mathrm{n}}\right)$ & $\mathrm{f}^{\prime}\left(\mathrm{a}_{\mathrm{n}}\right)$ & $\mathrm{C}=\mathrm{f}\left(\mathrm{a}_{\mathrm{n}}\right) / \mathrm{f}^{\prime}\left(\mathrm{a}_{\mathrm{n}}\right)$ & $\mathrm{a}_{\mathrm{n}+1}=\mathrm{a}_{\mathrm{n}}$ \\
\hline 1 & 1989.867456 & & & & \\
\hline 2 & 2011.982471 & 0.081520796 & -0.210603661 & -0.387081571 & 2012.369553 \\
\hline 3 & 2012.369553 & 0.081520796 & -0.21060366 & -0.387081571 & 2012.369553 \\
\hline 4 & 2012.369553 & 0.001774025 & -0.210478556 & -0.000115053 & 2012.369668 \\
\hline 5 & 2012.369668 & $3.56067 \mathrm{E}-09$ & -0.690469061 & $-5.15689 \mathrm{E}-09$ & 2012.369668 \\
\hline
\end{tabular}

After five iterations the number 2012.37 keeps repeating and so that is the value for "a" for those sets of parameters. Using calculated "a" of 2012.37 to design a catenary path for horizontal distance $2000 \mathrm{~m}$ to end of build.

Well 1 has a target at $3500 \mathrm{~m}$ TVD and a $10000 \mathrm{~m}$ horizontal distance from well origin, but the build section is to be designed from 0 to $826 \mathrm{~m}$. 


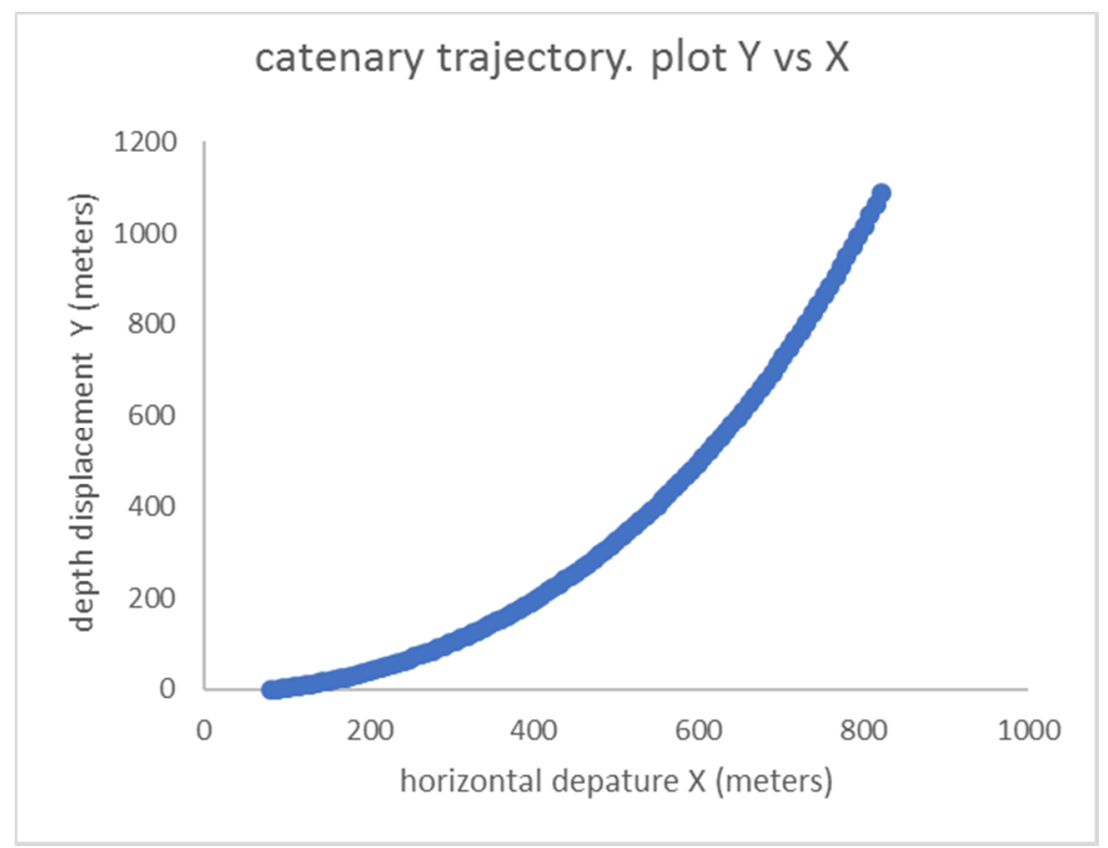

Figure 4. Catenary trajectory for well 1

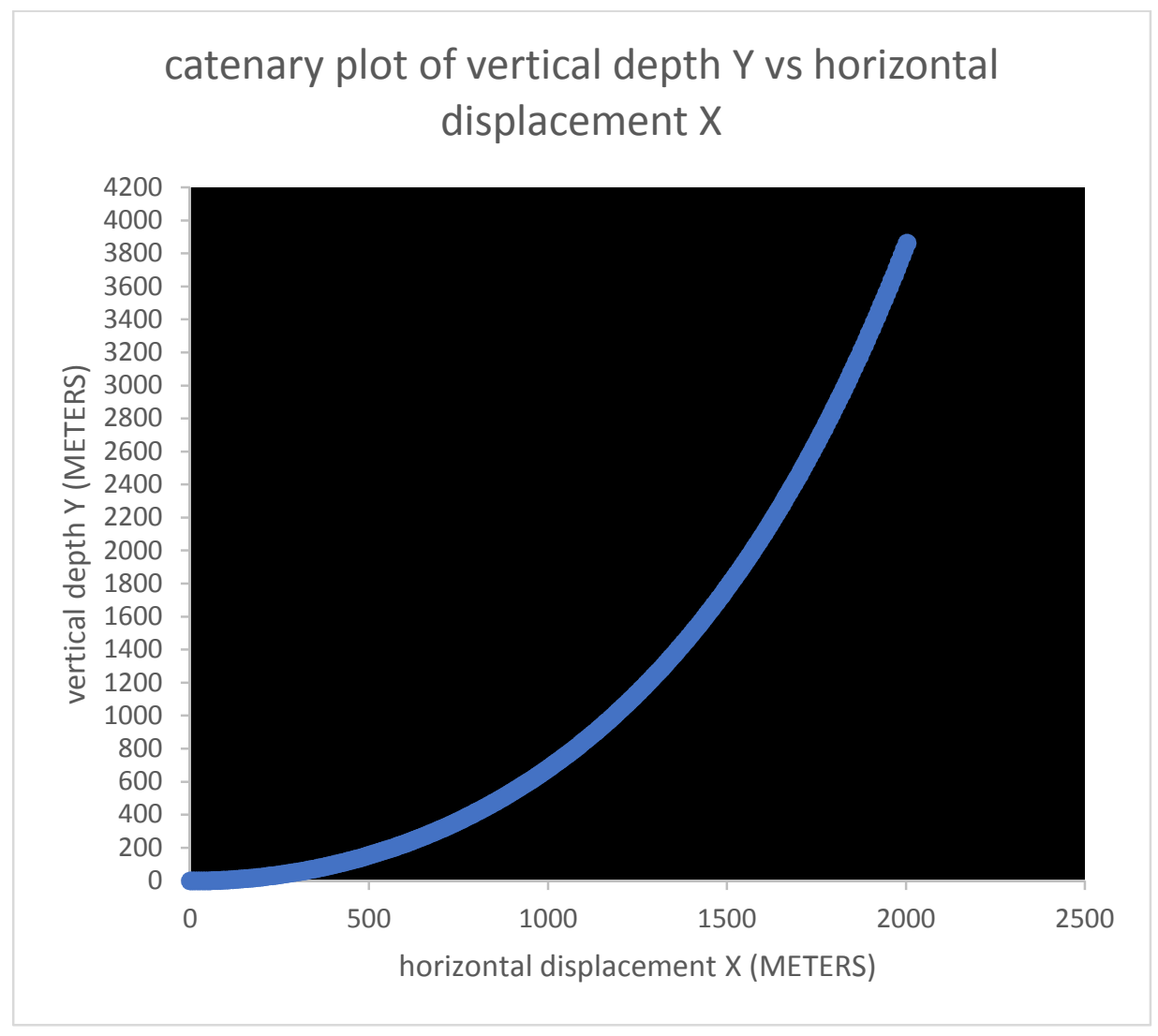

Figure 5 catenary trajectory for well 2.

\subsection{Discussions}

We considered the Newton-Raphson method as a tool for estimating the catenary parameter a, for use in the design of the buildup section of extended reach wells and applied it in the design of 2 buildup sections of 2 different wells. From the results obtained from applying the Newton-Raphson method on the two wells, the following was observed.

Analyzing figure 4.1, the kick off point for the catenary profile in well 1 will be at $596 \mathrm{~m}$, within the depth 
proposed in the design, followed by a constant build section to 10 degrees covering a total depth of $100 \mathrm{~m}$ since a catenary shape cannot start with a 0 degree angle. The catenary section will start at a depth of $696 \mathrm{~m}$ and end at a depth of $1550.1 \mathrm{~m}$ covering a TVD of $854.1 \mathrm{~m}$, the total length of the build section is $1516.04 \mathrm{~m}$ and dogleg severity of 2.404 degrees per $30 \mathrm{~m}$. From where the straight sail section will continue to target at $10000 \mathrm{~m}$, horizontal projection. The catenary parameter "a" used to design "well 1" is 418.0242078, and we propose to use a $65 / 8$ drill string with unit weight of $84.43 \mathrm{Ib} / \mathrm{m}$. using equation 3.07 we calculate tension needed to get shape and it will serve as tension at end of build.

$$
\begin{aligned}
& \mathrm{T}=418.024 *(25.6 * 0.0146) * 9.8 \\
& \mathrm{~T}=1531.159 \mathrm{KN}
\end{aligned}
$$

To achieve this tension at the end of the build we recommend a 5 5/8 diameter string of unit weight 0.37376 $\mathrm{KN} / \mathrm{m}$ be used to cover a measured depth of $7596 \mathrm{~m}$ and BHA assembly of and average of $1.2439 \mathrm{KN} / \mathrm{m} \mathrm{BHA}$ used for a measured depth of $1578 \mathrm{~m}$.

\section{Well 2}

The second well is a horizontal extended reach well with a proposed end of build at $2000 \mathrm{~m}$, TVD to target of 1805.5 and a horizontal distance to target at $8000 \mathrm{~m}$. The designed catenary and parabola trajectories are as follows. The designed catenary trajectory will begin at $725 \mathrm{~m}$ with an angle of 40.13 degrees, while the kick off point for the build section will begin at $525 \mathrm{~m}$, again within the depth proposed in our design with an initial build section for $200 \mathrm{~m}$ TVD from 0 to 40.13 degrees, recall a catenary shape cannot start with a 0 degree tangent. The catenary section will start at a depth of $725 \mathrm{~m}$ and end at a depth of $1805.5 \mathrm{~m}$ covering a TVD of $1060 \mathrm{~m}$, the measured length of the buildup section from calculations will be 2374.87 and the dogleg severity of 1.38 degrees per $30 \mathrm{~m}$, from where the straight horizontal sail section will continue to target at $8000 \mathrm{~m}$. The value of "a" used to design well $\mathrm{A}$ is 2040.221 , and we propose to use a $65 / 8$ drill string with unit weight of $84.43 \mathrm{Ib} / \mathrm{m}$. using equation 3.07 we calculate tension needed to get shape and it will serve as tension at end of build.

$$
\begin{aligned}
& \mathrm{T}=2012.369668 *(25.6 * 0.0146) * 9.8 \\
& \mathrm{~T}=7371.0042 \mathrm{KN}
\end{aligned}
$$

To achieve this tension at the end of the build a $55 / 8$ diameter string of unit weight $0.37376 \mathrm{KN} / \mathrm{m}$ buoyed weight, is used to cover a measured depth of $5000 \mathrm{~m}$ and BHA assembly of an average of $4.02 \mathrm{KN} / \mathrm{m} \mathrm{buoyed}$ weight is used for a measured depth of $1096 \mathrm{~m}$.

\section{Conclusion}

The use of the Newton-Raphson iterative method for the estimation of catenary parameter "a" for buildup section design of extended reach wells makes it easy for engineers to plan catenary trajectories with available materials and also removes the uncertainties that are inherent in predicting the shape of the trajectory. Uncertaintities remains of what tensions would be like in the well below but with this method the estimated parameter can be used to also estimate downhole tension values. This method is successful in predicting their individual parameters and also to predict maximum tensions to expect when drilling. These tensions are directly determined by friction and activity per time, and also the drillstring tension directly controls the magnitude of the catenary parameter. This method presents a way the iterated catenary parameter "a" can be successfully used to design the tension at the end of the build i.e. the BHA assembly to bring about the desired tension.

\section{Acknowledgement}

The author acknowledges Ibe Alonge Samuel for his contribution to the work

\section{References}

Aadnoy, B. S., Toff, V., \& Joannes D. (2006) Construction of Ultralong Wells Using a Catenary Well Profile. Paper presented at the IADC/SPE Drilling Conference, Miami, Florida, USA. doi: https://doi.org/10.2118/98890-MS

Bhalla, K. (1996). Achieving Extended Reach. Paper presented at the SPE Gulf Coast Section/ICoTA North American Coiled Tubing Roundtable, Conroe, Texas, doi: https://doi.org/10.2118/36347-MS

Chatterjee N. \& Nita G. N.(2010). The hanging cable problem for practical applications. Atlantic Electronic Journal of Mathematics Volume 4, Number 1, 70-77

Cunha, J.C., Martins, A.L., Sa, C.H.M., \& P. Dore Fernandes. (2002).Planning Extended Reach Wells for Deep Water. Paper presented at the SPE International Petroleum Conference and Exhibition in Mexico, Villahermosa, Mexico. doi: https://doi.org/10.2118/74400-MS

Deli G., Chenjin T \& Haixiong T. (2009) Limit analysis of extended reach drilling in South China Sea. Petroleum Science, vol 6(2), pp.166-171.

Dune K.K. (2004). Petroleum Engineering and The Industry "Energy information administration," Annual Report, U.S. Crude Oil, Natural Gas, and Natural Gas Liquids Reserves.

Fomin, O. (2019) Identifying and Recording Drill Pipe Operating Time Using RFID Tags. 
Gong, W. (1988). Directional Drilling Technology With The Parabola Method." Paper presented at the International Meeting on Petroleum Engineering, Tianjin, China, doi: https://doi.org/10.2118/17829-MS

Kamenskikh, S. (2015). Drilling Accidents Analysis in Timan-Pechora province. European North Resources. Technology and Economics of Development, no. 2

Liu, Xiushan, \& Robello Samuel. (2009). Catenary Well Profiles for Ultra Extended-Reach Wells. Paper presented at the SPE Annual Technical Conference and Exhibition, New Orleans, Louisiana.

Mason, C.J., \& A. Judzis. (1998). Extended-Reach Drilling -- What is the Limit? Paper presented at the SPE Annual Technical Conference and Exhibition, New Orleans, Louisiana.

Payne, M.L., Cocking, D.A., \& A.J. Hatch. (1994). Critical Technologies for Success in Extended Reach Drilling. Paper presented at the SPE Annual Technical Conference and Exhibition, New Orleans, Louisiana.

Rodman, D.W., and G. Swietlik. (1997). Extended Reach Drilling Limitations: A Shared Solution. Paper presented at the SPE Offshore Europe, Aberdeen, United Kingdom,. doi: https://doi.org/10.2118/38466-MS ROGTEC,: 78-92.

Sun T., Gao D. \& Zhang H. (2013).A new well profile for extended reach drilling.CMES, vol.90, no.1, pp.37-45, 2013

Xiaohua Z. \& Zhi Z. (2017). Design of an ultra-high torque double shoulder drill-pipe tool joint for extended reach well, Natural Gas Industry B, 4(5) pg 374-381

Zhang, S, Shi, W., Zhou, L., Zhang, L. \& Constantine M. (2020). Model Test of Monopile-Type Offshore Wind Turbine under Breaking Waves. Paper presented at the 30th International Ocean and Polar Engineering Conference. 